\title{
The evolutionary game analysis on the tacit knowledge sharing activities in the scientific research team of universities under the bounded rationality
}

\author{
Su Xikun, He Lirong \\ School of Business Administration, South China University of Technology, Guangzhou, China
}

Email address:

bmxksu@scut.edu.cn(SuXikun),xnlucas@163.com(HeLirong)

To cite this article:

Su Xikun, He Lirong. The Evolutionary Game Analysis on the Tacit Knowledge Sharing Activities in the Scientific Research Team of Universities under the Bounded Rationality. Science Innovation.Vol. 2, No.6, 2014, pp.77-81.doi: 10.11648/j.si.20140206.11

\begin{abstract}
The tacit knowledge sharing in the scientific research team of universities has important implications for the building and innovation of the research team. Under conditions of bounded rationality, this paper establishes the evolutionary game model of knowledge sharing in the scientific research team of universities. By solving the replicator dynamics function,this paper is to judge the mechanism and path of the dynamic evolution of the knowledge-sharing in the scientific research team and to analyze the influencing factors of tacit knowledge sharing in university research team from the sharer, the recipient and the objective factors. According to the results, this paper develops effective strategies to promote knowledge sharing in the scientific team of universities.
\end{abstract}

Keywords: Scientific Research Team of University,Tacit Knowledge Sharing Activities,Bounded Rationality, Evolutionary Game

\section{Research Background}

British physical chemist and philosopher Michael Polanyi [1] believes that knowledge can divided into explicit knowledge and tacit knowledge, tacit knowledgeexists in the minds of individuals and difficult to formalize and understand in a particular environment, whichis a significant part of knowledge innovation. Tacit knowledgeis a source of universities innovation and can bring a competitive advantage. Long Jian [2] thinks that since university is a knowledge-intensive organization, knowledge is a core resource in it.

Currently,there are a lot of researches on the tacit knowledge sharing activities in the scientific research team of universities. Liu Juan[3] draws that knowledge sharing in universities is possible by building a college game model of knowledge sharing on the basis of the elaboration of knowledge and its characteristics. By studying the different structures and media adaptation in university research team communication networks, Yang Zhenhua and Shi Qinfen[4]proposeteam's tacit knowledge disseminationcapabilities is different due to differentdissemination functions.XueYajiong,John Bradley and Liang Huigang[5] study the factors related the tacit knowledge sharing in the universities from organizational climate and leadership, which analyzefactors related to the outside world, characteristics of tacit knowledge, and self-interest of the main.

From the perspective of the subject bounded rationality, this paper uses evolutionary game to study, attempts to explore the dynamic evolution of a stable path and the impact of this resultof knowledge sharers and monopolies inthe tacit knowledge sharing process, finally develops appropriate strategies to promote the tacit knowledge sharingin the scientific research team of universities.

\section{Bounded Rationality and Evolutionary Game of Tacit Knowledge Subject}

Based on the "perfectly rational", classical economic theory thinks that makers not only pursue their own best interestswhile meeting the analytical reasoning ability to pursue their own best interests.Herbert - A - Simon [6] thinkspeople is "economic man in bounded rationality" between completely rational and irrational state rather than “economic man in fully rationality".Makers can't find the optimal decisioneasily,they need to learncontinuouslyin order 
to find the best strategyafter repeated learning by trial and error.

Evolutionary game theory is a theory which developed on the basis of biology and classical game theory.XieShiyu[7] pointsevolutionary game theory is bounded rationality and learning instead of completely rationality, which is closer to reality and the whole game is a dynamic process of stabilizing.Game player will not be able to find the optimal strategy at first, theyneed tolearncontinuously in order to find the best strategyafter repeated learning by trial and error. Balance is not a one-time choice, but a constantly adjusted and improved result and may deviate again even in balance.Evolutionary game pays more attention to personal bounded rationality of economic policymakers, achieves consistent between individual rationality and collective rationality through the design and optimization of rules, mechanisms and systems.

As a special shared resource,tacit knowledge can't survive without the principal who has knowledge.At the same time, knowledge sharing is a strict two-way process, interactions between individuals, which belong to the micro level of individual behavior. Thus tacit knowledgesharing is bound to be affected by individual bounded rationality. Their actions and revenue are not clear when people want to carry out individual knowledge sharing.In the knowledge-sharing process, peoplecan get their own optimal strategythrough continuous learning and adjustment and may also deviate from the optimal strategy againbecause of restrictions on their ability to recognize. By continuous learning and judgment, makers continue to learn and improve their ability to optimize the strategy, thus the efficiency of organizations has been optimizedand obtain maximum benefits.

\section{Evolutionary Game Model of Tacit Knowledge Sharing}

High cost, high risk and the uncertainty of income distributionexist in the tacit knowledge innovation process, and thus the knowledge owner takes the attitude of monopolizing the knowledge because of self-interest. So there is a game process of knowledge sharing between the subjects of knowledge.University research team is constituted by the supervisor and the student, supervisors grasp the forefront, high-end and extensive knowledge in the research team, and students are poor atknowledgebecause of their experience, which form a knowledge gap.Tacit knowledge gap can contribute to knowledge sharing among team members.

There are two types of hidden subject of knowledge, one is sharing of skeptics of non-cooperation, and the other is the cooperative people who share preferences.A member ofboth groupsisrandomly paired and to game repeatedly when we analyze.In order to express conveniently and uniformly, $\pi_{i}$

$(i=1,2)$ means value created by their own knowledge that who refuse to knowledge sharing among members, $k_{i}(\mathrm{i}=1,2)$ means knowledge storage capacity of members, the higher the volume, the more tacit knowledge members have.The sharer's ability, media richness in communication channels and the recipient'sability caninfluence the transfer of knowledge due to the abstract, external characteristics and ambiguity of tacit knowledge. $r_{i}(\mathrm{i}=1,2)$ means transfer capability of the sharer.When the spread willingness is identical, the larger ability of the sharer, the more effective dissemination and transfer of tacit knowledge, thus $k_{i} r_{i}$ can be used to represent the transfer of the knowledge volume of knowledge subject. $S_{i}(\mathrm{i}=1,2)$ means media richness in communication channels,Daft, R. L.,Lengel,R.H[8] proposes media richness theory is the richness of transfer information is different due to different media when people are in different tasks and problems, the higher the volume, the more accuracy of the media. Receiver's ability to absorb decide whether recipients can absorb knowledge, the greater the volume, the stronger of the absorption capacity, and absorptiveability is determined by the accumulated knowledge, difference degree of knowledge background and subjective personal effort degree. Thus the direct benefits created by the knowledge sharing is: $t_{i} k_{j} r_{j} s_{j} \quad(\mathrm{i}, \mathrm{j}=1,2)$ 。

As knowledge-intensive organizations, the innovation of the research team is the driving force and source of college sustainable development.New value can be created through the flow of tacit knowledge transfer and absorption. $p_{i} \quad(\mathrm{i}=1,2)$ means the innovation capacity of knowledge internalization of the knowledge subject, the value created by innovation knowledge is influenced by the transfer of their own knowledge and absorption of knowledge of other body, so benefits created by the innovation is: $p_{i}\left(k_{i} r_{i}+t_{i} k_{j} r_{j} s_{j}\right)$ ( $\mathrm{i}$, $\mathrm{j}=1,2)$.

Table 1.Tacit knowledge sharing game payoff matrix.

\begin{tabular}{llll}
\hline & \multicolumn{2}{l}{ Knowledge subject1 } & Knowledge unsharing \\
\cline { 2 - 4 } & Knowledge sharing & & $\pi_{1}-l_{1} k_{1} r_{1}, \pi_{2}$ \\
\hline \multirow{3}{*}{ Knowledge subject 2 } & Knowledge sharing & $\pi_{1}+t_{1} k_{2} r_{2} s_{2}+p_{1}\left(k_{1} r_{1}+t_{1} k_{2} r_{2} s_{2}\right)-l_{1} k_{1} r_{1}$, & $\pi_{1}, \pi_{2}$ \\
& & $\pi_{2}+t_{2} k_{1} r_{1} s_{1}+p_{2}\left(k_{2} r_{2}+t_{2} k_{1} r_{1} s_{1}\right)-l_{2} k_{2} r_{2}$ & \\
\hline
\end{tabular}

The transfer of the tacit knowledge may lead to the loss of competitive advantage and social recognition of the knowledge subject, thus risk is huge while sharing knowledge. What's more, transfer cost of the knowledge sharing also exists in the transfer process due to the fuzzy and uncertainty of tacit knowledge. This paper uses $l_{i}$ to represent risk factor and sharing cost, thus the cost and 
disutility in the process of knowledge sharing is: : $l_{i} k_{i} r_{i}(\mathrm{i}=1$, 2).Finally, tacit knowledge sharing game payoff matrix is set up(Table 1).

\section{Calculation and Analysis of theEvolutionary Game Model of Tacit Knowledge Sharing}

\subsection{Calculation of Evolutionary Game Model of Tacit Knowledge Sharing}

Academic performance of university research team members is a gradual process, not all game players adjust at the same time, so the dynamic evolution equation of the evolution replicator dynamicsequation can be used to represent strategy adjustment speed. Replicator dynamicsmodel was developed by Taylor and Jonker [9], which can describe the group behavior trend of the bounded rational individual and predict the groupbehavior of the individual accurately. Thus sharing strategy selection problemin the process of tacit knowledge sharing can be solved through the use of evolutionary game theory on the basis of bounded rationality.

Given in the university research team, knowledge subject 1 's choice of the proportion of knowledge-sharing strategy is $\mathrm{x}$, knowledge unsharing is 1-x; knowledge subject 2's choice of the proportion of knowledgesharing strategy is $y$, knowledge unsharing is 1-y. Two types of knowledge subjects are randomly paired and to game repeatedly.

The benefit of sharing strategy of the knowledge subject 1 is:

$$
U_{1 e}=y \cdot\left[\pi_{1}+t_{1} k_{2} r_{2} s_{2}+p_{1}\left(k_{1} r_{1}+t_{1} k_{2} r_{2} s_{2}\right)-l_{1} k_{1} r_{1}\right]+(1-y)\left[\pi_{1}-l_{1} k_{1} r_{1}\right]=y t_{1} k_{2} r_{2} s_{2}+y p_{1}\left(k_{1} r_{1}+t_{1} k_{2} r_{2} s_{2}\right)+\pi_{1}-l_{1} k_{1} r
$$

The benefit of unsharing strategy of the knowledge subject 2 is:

$$
u_{1 n}=y \cdot \pi_{1}+(1-y) \cdot \pi_{1}=\pi_{1}
$$

Thus, average benefit of the knowledge subject 1 is:

$$
\bar{u}_{1}=x \cdot u_{1 e}+(1-x) u_{1 n}=x \cdot\left[y t_{1} k_{2} r_{2} s_{2}+y p_{1}\left(k_{1} r_{1}+t_{1} k_{2} r_{2} s_{2}\right)-l_{1} k_{1} r_{1}\right]+\pi_{1}
$$

Similarly, average benefit of the knowledge subject 2 is:

$$
\bar{u}_{2}=y \cdot u_{2 e}+(1-y) u_{2 n}=y \cdot\left[x t_{2} k_{1} r_{1} s_{1}+x p_{2}\left(k_{2} r_{2}+t_{2} k_{1} r_{1} s_{1}\right)-l_{2} k_{2} r_{2}\right]+\pi_{2}
$$

Next, we build replicator dynamicsequation of knowledge subject 1 and knowledge subject 2 .

Replicator dynamicsequation of knowledge subject 1 is:

$$
\mathrm{d} x / d t=x \cdot\left[u_{1 e}-\bar{u}_{1}\right]=x(1-x)\left[y t_{1} k_{2} r_{2} s_{2}-l_{1} k_{1} r_{1}+y p_{1}\left(k_{1} r_{1}+t_{1} k_{2} r_{2} s_{2}\right)\right.
$$

Replicator dynamicsequation of knowledge subject 2 is:

$$
\mathrm{dy} / d t=y \cdot\left[u_{2 e}-\bar{u}_{2}\right]=y(1-y)\left[x t_{2} k_{1} r_{1} s_{1}-l_{2} k_{2} r_{2}+x p_{2}\left(k_{2} r_{2}+t_{2} k_{1} r_{1} s_{1}\right)\right]
$$

Calculating and analyzing the replicator dynamics equation of knowledge subject 1 firstly. If:

$$
y^{*}=\frac{l_{1} k_{1} r_{1}}{t_{1} k_{2} r_{2} S_{2}+p_{1}\left(k_{1} r_{1}+t_{1} k_{2} r_{2} S_{2}\right)}
$$

Then, $\mathrm{dx} / \mathrm{dt}$ is 0 , which means all $\mathrm{x}$ are stable; If

$$
y^{*} \neq \frac{l_{1} k_{1} r_{1}}{t_{1} k_{2} r_{2} S_{2}+p_{1}\left(k_{1} r_{1}+t_{1} k_{2} r_{2} S_{2}\right)}
$$

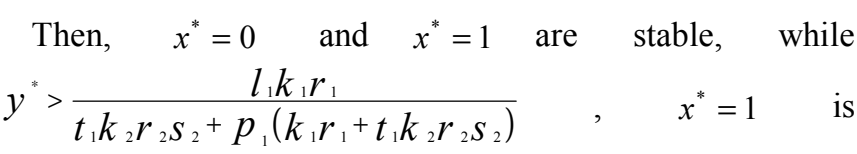
evolutionarystable strategy(ESS) and represents knowledge subject 1 is tending to knowledge sharing; while $y^{*}<\frac{l_{1} k_{1} r_{1}}{t_{1} k_{2} r_{2} S_{2}+p_{1}\left(k_{1} r_{1}+t_{1} k_{2} r_{2} S_{2}\right)} \quad, \quad x^{*}=0 \quad$ is evolutionarystable strategy(ESS) and represents knowledge subject 1 is tending toknowledge unsharing. Similarly, if:

$$
x^{*}=\frac{l_{2} k_{2} r_{2}}{t_{2} k_{1} r_{1} S_{1}+p_{2}\left(k_{2} r_{2}+t_{2} k_{1} r_{1} S_{1}\right)},
$$

Then,dy/dt is 0 , which means all y are stable. If:

$$
x^{*}>\frac{l_{2} k_{2} r_{2}}{t_{2} k_{1} r_{1} S_{1}+p_{2}\left(k_{2} r_{2}+t_{2} k_{1} r_{1} S_{1}\right)}
$$


Then $y^{*}=1$ is evolutionary stable strategy(ESS) and represents knowledge subject 2 is tending to knowledge sharing.

If:

$$
x^{*}<\frac{l_{2} k_{2} r_{2}}{t_{2} k_{1} r_{1} S_{1}+p_{2}\left(k_{2} r_{2}+t_{2} k_{1} r_{1} S_{1}\right)}
$$

Then $y^{*}=0$ is evolutionary stable strategy(ESS) and represents knowledge subject 1 is tending to knowledge unsharing.

According to the above analysis, we can know dynamic evolution figure of the knowledge sharing strategy of the knowledge subject 1 and knowledge subject 2(Figure 1).

From the figure 1, we can know that the tacit knowledge sharing activities in the scientific research team of universitieshave five partial equilibrium points, $(1,0)$ and $(0$, 1) are unstable equilibrium points, $\left(x^{*}, y^{*}\right)$ is a saddle point, while $(0,0)$ and $(1,1)$ are stable, which means knowledge subject 1 and knowledge subject 2 select the tacit knowledge sharing simultaneously or the tacit knowledge unsharing. The game will converge to the evolutionary stable strategy $(1,1)$ and the two knowledge subjects select the knowledge sharing when the initial state of the game fell on the $\mathrm{B}$ region.The game will converge to the evolutionary stable strategy $(0,0)$ and the two knowledge subjects select the knowledge unsharing when the initial state of the game fell on the $\mathrm{C}$ region.

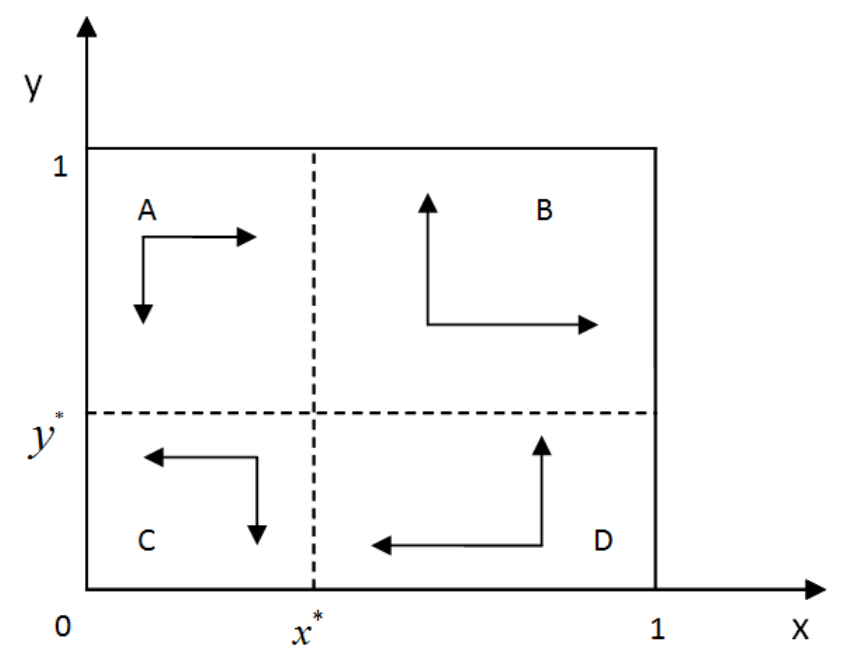

Figure 1.Dynamic evolution chart of the knowledge sharing strategy of the knowledge subject 1 and knowledge subject 2.

\subsection{Analysis of Evolutionary Game Model of Tacit Knowledge Sharing}

As can be seen from the analysis of dynamic evolution figure, different initialconditions of thegame lead to different equilibrium results. The proportion of participants who choose strategy initially decide knowledge sharing or knowledge monopolization that research team forms, and the key factor influences the proportion of participants is the benefit of the knowledge subject, while benefit is affected by different factors of the knowledge sharing and the more effective factor influenceis that the knowledge of the initial state of the subject area falls on the B region. We can develop different strategies from different aspects so as to promote university research team tacit knowledge subject knowledge transfer to the maximum extent, and constantly enhance the vitality of university research teams and improve the innovation ability of the team.

\subsubsection{Sharer Factors: Transfer Capability and Media Richness}

Burton R.Clarkthinks that there are a lot of tacit knowledge in real scientific research from the perspective of the science in his book and tacit knowledge are the scientific community support, research groups and researchers. The media richness of the transfer channels can influence the effect of the knowledge sharing. In fact, the volume of the knowledge sharing can be increased by improvingthe transfer capability of the knowledge sharers and media richness, we can know that $x^{*}$ is monotonic decreasing function of the transfer capability and $y^{*}$ is monotonic decreasing function of the media richness from the solution of the replicator dynamics equation. $x^{*}$ and $y^{*}$ are small while increase the transfer capability of the knowledge sharers and media richness, B region will expand, which means scientific research team' ESS is tending to knowledge sharing.

\subsubsection{Recipient Factors: the Ability to Absorb and Valueinternalization}

The absorptive capacityof the knowledge recipient not only affects the absorption to gain new knowledge and internalize the knowledge to create new value, but also affects the willingness of both knowledge sharing knowledge sharers.Cohen and W. Levinthal[10] draw that accumulated knowledge, the different degree of the knowledge background and degree of efforts.Research team needs to be a combination of differentiated background knowledge of workers, while strengthening and encouraging the subjective effort of members.In fact, the greater the ability of the recipient to absorb, the larger amount of tacit knowledge to accept.With the continuousincreasement in the amount of tacit knowledge and the research methods and skills of the knowledge subject, the amount of knowledge of the subject will continue to increase.In addition, the enhancementof the tacit knowledge sharing in the team can help create a good atmosphere of knowledge sharing, thus increasing the willingness and behavior of the knowledge sharing of the knowledge subject.

For the university research team, the value of the research team isinnovation. $x^{*}$ ismonotonic decreasing function of the ability to absorb and $y^{*}$ is monotonic decreasing function of thevalueinternalization. Improve the ability to absorb and internalize creative value can expand B region, which can help the ESS of team tend to share strategy.

\subsubsection{Objective Factors:Knowledge Sharing Risk Factors and Knowledge Gaps}

The risk factors and cost of the tacit knowledge sharing 
areaffected by two factors, one is the tacit knowledge is fuzzy, the other is the loss of authority and risk cost in tacit knowledge subject due to knowledge sharing. From the replicatordynamicsequation, $x^{*}=\frac{l_{2} k_{2} r_{2}}{t_{2} k_{1} r_{1} S_{1}+p_{2}\left(k_{2} r_{2}+t_{2} k_{1} r_{1} S_{1}\right)}$ is the monotonicincreasing function of the risk factor $l_{i}$, so asthe $y^{*}=\frac{l_{1} k_{1} r_{1}}{t_{1} k_{2} r_{2} s_{2}+p_{1}\left(k_{1} r_{1}+t_{1} k_{2} r_{2} s_{2}\right)}$. Research team can take effective way to reduce the value of the risk factors and promote knowledge sharing. In addition,we should enhance the sense of honor and meet the needs of the members, reduce the cost of knowledge sharing.According to the characteristics of students, increase student experience of success and self-confidence, encourage students through tangible forms of subsidies and scholarshipsand enhance students' awareness of the benefits of knowledge sharing by the way of seminars.

In fact, moderate knowledge gap is the basis of stimulate knowledge sharing among team members. The larger knowledge gap among members, the greater willingness to share. $x^{*}, y^{*}$ are the monotonic decreasing function of the knowledge gap, improve the knowledge gap can expand B region, which can help the ESS of team tend to tacit sharing strategy.

\section{Conclusion}

Evolutionary game theory is aneffective way to evaluate the internal knowledge sharing mechanism theory of the university research team, which has realistic meanings when we analyze the stable balance relation of the knowledge sharing. Through the use ofreplicator dynamics model of the evolutionary game theory, this paper explores the mechanism and path of the knowledge sharing evolution among members in the scientific research team of universities, analyzes the factors of the knowledge sharing and provides a theory evidence for finding a reasonable knowledge management methods and strategies. Universities can build the mechanism of the knowledge sharing from several points: (1) John Harsanyi[11]draws that human's behavior can be encouraged via economic benefit and social recognition. We should improve the satisfaction and achievement of the knowledge sharing among research team members and give spiritual and material incentives. (2) Building a knowledge sharing platform and enriching media richness of knowledge dissemination channels. Face to face communication mechanisms of the research team should be institutionalized and lectures and seminars should be regularlyholded. We also need to strengthen the ability to study of the individual, improve the ability to transfer and absorption of knowledge and facilitate the transfer of the tacit knowledge. (3)Strengthening communication and cooperation, enhancing trust among team members,buildinga sound knowledge protection mechanism of the team and reducing the risk and transfer cost of the knowledge sharing. Finallywe should create aharmonious team atmosphere of knowledge sharing and improve member willingness toshare knowledge.

\section{References}

[1] Michael Polanyi, 1958, "Personal Knowledge", University of Chicago Press.

[2] Long Jian, 2009, "Review of Tacit Knowledge Management of University”, Library, vol.6, pp54-59.

[3] Liu Juan, 2007, "Game Analysis of possibility of the University Knowledge Sharing”, Academia Bimestris, vol.3, pp 156-161.

[4] Yang Zhenhua, Shi Qinfen, 2007, "Media Practicality and Tacit Knowledge Dissemination of the University Research Team Communication Network", Science \& Technology Progress and Policy, vol.24, pp 115-117.

[5] XueYajiong, John Bradley, Liang Huigang, 2010, "Team Climate, Empowering Leadership, and Knowledge Sharing", Journal of Knowledge Management, vol.15, pp299-312.

[6] Herbert A. Simon, 1955, "A Behavioral Model of Rational Choice", The Quarterly Journal of Economics, vol.69, pp 99-118.

[7] XieShiyu, 2001, "Evolutionary Game Theory under Bounded Rationality", Journal of Shanghai University of Finance and Economics, vol.5, pp 3-9.

[8] Daft, R. L.,Lengel, R. H, 1996, "Organization Information Requirements, Media Richness and Structural Design", Management Science, pp 554-571.

[9] Taylor PDLB Jonker, 1978, "Evolutionarily Stable Strategy and Game Dynamics", Mathematical Biosciences, vol.40, pp 145-156.

[10] Cohen, W. Levinthal, D, 1990, “Absorptive Capacity: A New Perspective on Learning and Innovation", Administrative Science Quarterly, pp1128-1152.

[11] Harsanyi, J, 1969, "Rational Choice Models of Behavior Versus Functionalist and Conformist Theories", World Politics, vol.21, pp 513-538. 